INDONESIAN HEALTH ISSUE

\title{
Hubungan Pengetahuan Dan Sikap Ibu Dengan Status Gizi Selama Kehamilan Trimester Pertama
}

\author{
Parningotan Simanjuntak ${ }^{1}$, Plora Novita Febrina Sinaga ${ }^{2}$, Nopalina Suyanti \\ Damanik $^{3}$, Markus Dody Simanjuntak ${ }^{4}$
}

1-4 STIKes Mitra Husada Medan

Email korespondensi: aldo.alrez@gmail.com

ARTICLE INFO Article History:

Received

01 Januari 2022

Accepted

14 Februari 2022

Published

19 Februari 2022

\section{Kata Kunci:}

Pengetahuan;

Sikap;

Status Gizi

\section{Keywords:}

Knowledge;

Atittude;

Nutrional Status;

\author{
No HP: 081370990795
}

ABSTRAK
Latar Belakang: Kekurangan gizi selama kehamilan akan mempengaruhi
pertumbuhan, pembentukan dan perkembangan organ serta fungsi organ
janin menjadi kurang optimal dikhawatirkan akan terjadi cacat bawaan
pada bayi yang dilahirkan bahkan bisa juga ukuran kepala bayi kecil
karena kurangnya asupan gizi janin untuk perkembangan otak sehingga
perkembangan otak tidak optimal. Tujuan: untuk mengidentifikasi
Hubungan Pengetahuan Dan Sikap Ibu Dengan Status Gizi Selama
Kehamilan Trimester Pertama. Metode: Jenis penelitian kuantitatif
dengan rancangan cross sectional dengan sampel 30 ibu hamil waktu
penelitian desember sampai bulan mei 2021 dan analisi data dengan
menggunakan uji chi-square. Hasil: Berdasarkan hasil uji chi-square
didapat ada hubungan pengetahuan ( $\mathrm{p}=0,002$ ) dan sikap ( $\mathrm{p}=0,000$ ) ibu
hamil dengan status gizi selama kehamilan trimester Pertama.
Kesimpulan: Ada hubungan pengetahuan dan sikap ibu dengan status
gizi selama kehamilan trimester pertama. Disarankan kepada ibu hamil
agar memeriksakan serta mengontrol kehamilan kepada petugas
kesehatan sehingga mengurangi resiko kekurangan gizi.

\begin{abstract}
Background: Malnutrition during pregnancy will affect the growth, formation and development of organs and functions of the fetal organs to be less than optimal, it is feared that there will be congenital defects in babies born even the size of the baby's head is small due to lack of fetal nutrition for brain development so that brain development does not occur. optimally (Pujiastuti, 2015). Purpose: to identify the relationship between knowledge and attitudes of mothers with nutritional status during the first trimester of pregnancy. Methods: This type of research is quantitative with a cross sectional design with a sample of 30 pregnant women from December to May 2021 and data analysis using the Chi-square test. Results: Based on the results of the chi-square test, it was found that there was a relationship between knowledge $(p=0.002)$ and attitudes $(p=0.000)$ of pregnant women with nutritional status during the first trimester of pregnancy. Conclusion: There is a relationship between knowledge and attitudes of mothers with nutritional status during the first trimester of pregnancy. It is recommended for pregnant women to check and control their pregnancy to health workers so as to reduce the risk of malnutrition.
\end{abstract}

(C) 2021 by the authors. Submitted for possible open access publication under the terms and conditions of the Creative Commons Attribution (CC BY SA) license (https://creativecommons.org/licenses/by-sa/4.0/). 


\section{PENDAHULUAN}

Kehamilan merupakan proses fisikologis bagi wanita yang dimulai dengan proses fertilisasi kemudian janin berkembang di dalam uterus dan berakhir dengan kelahiran. Pemahaman tentang konsep dasar kehamilan mulai dari fertilisasi hingga janin aterm, mendiagnosa kehamilan dan menghitung usia kehamilan sangat penting untuk mendapatkan penjelasan kepada ibu hamil serta dapat memberikan asuhan sesuai dengan perubahan yang terjadi selama periode kehamilan. Kehamilan dimulai ketika satu sel telur yang di keluarkan oleh salah satu ovarium pada masa ovulasi menyatu dengan satu dari ratusan juta sel sperma yang disebut fertilisasi. Sel telur yang sudah di buahi menjadi zigot berjalan menuju dinding uterus menanamkan diri. Penanaman zigot ke dinding uterus disebut implantasi.[Kasmiati,2020]

Angka kematian ibu (AKI) di Indonesia masih cukup tinggi. Hal tersebut memiliki capaian penurunan AKI di beberapa negara Asean. AKI Di negara-negara Asean sudah mencapai posisi 40-60 per 100 ribu kelahiran hidup. Sedangkan di Indonesia pada tahun 2015 masih menempati posisi 305 per 100 ribu kelahiran hidup. Hal ini beda jauh dengan Singapura yang berbeda 2-3 AKI per 100 ribu kelahiran (SUPAS, 2015). Sementara itu, data capaian kinerja Kemenkes RI tahun 2015-2017 menunjukkan telah terjadi penurunan jumlah kasus kematian ibu. Jika AKI tahun 2015 mencapai 4.999 kasus, maka pada tahun 2016 dan 2017 sedikit mengalami penurunan menjadi 4.912 kasus dan 1.712 kasus. Meski menglami penurunan, nampaknya AKI masih menjadi salah satu fokus utama pemerintah.[Masturah,2013]

Kehamilan memang membawa banyak perubahan dalam tubuh seorang wanita, mulai dari kondisi hormon hingga bentuk tubuh tujuannya untuk menjaga kehamilan itu sendiri, akan tetapi perubahan yang dirasakan setiap wanita. Contohnya plasenta, sebagai organ endokrin, plasenta menghasilkan berbagai hormone seperti estrogen, progesterone dan HCG. Peningkatan produk estrogen berpengaruh pada pembesaran uterus, mamae organ genital, retensi cairan yang menyebabkan pertambahan natrium perubahan disposisi lemak dan faktor pembekuan dalam darah, relaksasi persendian, penurunan produksi asam klorida dan pepsin dalm lambung, sedangkan progesterone memicu pertumbuhan endometrium, penumpukan lemak ibu, peningkatan retensi natrium dan pelemasan jaringan otot polos.[Widiasih,2020]

Adanya perubahan tersebut akan sangat mempengaruhi kebutuhan gizi ibu hamil yang bertujuan untuk memaksimalkan pertumbuhan dan perkembangan janin. Prinsip umum yang perlu diperhatikan dalam memenuhi kebutuhan gizi ibu hamil adalah makanan sehat dan seimbang yang harus di konsumsi ibu selama masa kehamilannya dengan porsi dua kali makan orang yang tidak hamil. Normalnya sang ibu mengalami peningkatan berat badan selama kehamilan berlangsung. Kenaikan berat badan yang optimal akan berdampak baik pada kehamilan maupun output persalinannya kelak. Dengan berat badan yang ideal untuk seorang ibu hamil pertumbuhan janin pada umumnya akan berlangsung normal. Komplikasi timbulnya gangguan kesehatan dan penyakit lain juga bisa dihindari dengan ini dapat memberika efek pacsapersalinan yaitu kesehatan ibu selama laktasi.[Fransiska,2020]

Program EMAS berupaya menurunkan angka kematian ibu dan angka kematian neonatal dengan cara Meningkatkan kualitas pelayanan emergensi obstetri dan bayi baru lahir minimal di 150 Rumah Sakit PONEK dan 300 Puskesmas/ askesmas PONED dan 2 memperkuat sistem rujukan yang efesien dan efektif antar puskesmas dan Rumah sakit. Upaya percepatan penurunan AKI dapat dilakukan dengan menjamin agar setiap ibu mampu mengakses pelayanan kesehatan ibu yang berkualitas, seperti pelayanan kesehatan ibu hamil, pertolongan persalinan oleh tenaga kesehatan terlatih di fasilitas pelayanan kesehatan, perawatan pacsa persalinan bagi ibu dan bayi, perawatan khusus dan rujukan jika terjadi komplikasi, kemudahan mendapatkan cuti hamil dan melahirkan, dan pelayanan keluarga berencana. Dari 6 provinsi tersebut yang mengalami angka kematian terbesar salah satunya adalah Sumatera Utara.[Anis,2017]

Jumlah kematian ibu di Kota Medan tahun 2016 sebanyak 3 jiwa dari 47.541 kelahiran hidup, dengan Angka kematian ibu (AKI) dilaporkan sebesar 6 per 100.000 kelahiran hidup yang artinya dari 100.000 kelahiran hidup 6 ibu meningggal saat kehamilan, persalinan atau 
nifas. AKI di kota Medan mengalami penurunan bila dibandingkan tahun sebelumnya. Pada tahun 2015, jumlah kematian ibu sebanyak 6 jiwa dari 49.251 kelahiran hidup. Tahun 2014, jumlah kematian ibu sebanyak 7 jiwa dari 48.352 kelahiran hidup dengan AKI sebesar 14 per 100.000 kelahiran hidup dan di tahun 2013 jumlah kematian ibu sebanyak 9 jiwa dengan AKI sebesar 21 per 100.000 kelahiran hidup.[SDKI,2017]

Pada umumnya kebutuhan gizi ibu hamil relatif tinggi dibandingkan kebutuhan gizi sebelum hamil. Pentingnya kebutuhan gizi pada ibu hamil bertujuan untuk memenuhi kebutuhan gizi pada ibu dan janin yang dikandungnya. Selain itu, kebutuhan gizi yang cukup juga bertujuan untuk persiapan ibu pada saat persalinan agar tidak menimbulkan masalah atau gangguan kesehatan dan mempersiapkan ibu untuk dapat menyediakan cadangan sejumlah energi (500 kalori) yang diperlukan untuk aktivitas bayinya.[lbnu,2020]

Kekurangan gizi selama kehamilan akan mempengaruhi pertumbuhan, pembentukan dan perkembangan organ serta fungsi organ janin menjadi kurang optimal dikhawatirkan akan terjadi cacat bawaan pada bayi yang dilahirkan bahkan bisa juga ukuran kepala bayi kecil karena kurangnya asupan gizi janin untuk perkembangan otak sehingga perkembangan otak tidak optimal. Selain itu kematian bayi karena BBLR yaitu kurang dari $2,5 \mathrm{~kg}$ dan bayi prematur, juga karena status gizi ibu yang kurang.[Puspitaningrum,2017]

Faktor-faktor yang mempengaruhi ibu hamil dalam pemenuhan gizi antara lain kebiasaan dan pandangan wanita terhadap makanan, ekonomi, pengetahuan zat gizi dalam makanan, dan status kesehatan. Jika sikap ibu hamil dalam penemuan gizi tidak segera terealisasi, akan berisiko terhadap janin yang dikandungnya. Malnutrisi bukan hanya melemahkan fisik dan membahayakan jiwa ibu, tetapi juga mengancam keselamatan janin. Wanita yang tetap hamil disaat status gizinya buruk, berisiko melahirkan bayi dengan berat badan rendah 2-3 kali lebih besar dibandingkan mereka yang berstatus gizi baik.[Puspitaningrum,2018]

Hasil survei awal dilokasi penelitian yaitu klinik kita $\mathrm{Br}$ Sembiring, peneliti menemukan informasi bahwa jumlah ibu hamil sebanyak 30 orang, dimana 12 ibu hamil diantaranya tidak mengerti status gizi selama kehamilan. Selain itu, peneliti juga menemukan masih terdapat masalah pada sikap yang tidak baik dalam pemenuhan gizi yang belum terpenuhi.

Berdasrkan latar belakang tersebut peneliti tertarik untuk mengetahui apakah ada antara hubungan pengetahuan dan sikap ibu hamil dengan status gizi selama kehamilan trimester pertama

\section{METODE PENELITIAN}

Penelitian ini merupakan penelitian kuantitatif. Penelitian ini menggunakan jenis penelitian korelasional. Jenis penelitian ini digunakan untuk mengetahui hubungan dan tingkat hubungan antara dua variabel atau lebih tanpa ada upaya untuk mempengaruhi variabel tersebut sehingga tidak terdapat manipulasi variable. Penelitian ini dilaksanakan mulai Bulan Maret s/d Juli Tahun 2021. populasi dalam penelitian ini adalah semua ibu hamil yaitu sebanyak 30 Orang.

Teknik pengambilan sampel dengan menggunakan teknik total sampling. Yaitu seluruh populasi dalam penelitian itu sebanyak 30 orang. 
HASIL PENELITIAN

berikut:

Hasil penelitian menunjukkan bahwa dari 30 orang ibu hamil didapatkan hasil sebagai

Tabel 1 Distribusi Karakteristik Responden Berdasarkan Umur, Pendidikan, Pekerjaan dan Usia Kehamilan

\begin{tabular}{|c|c|c|c|}
\hline No. & Karakteristik & Frekuensi & Persentase (\%) \\
\hline \multicolumn{4}{|c|}{ Umur } \\
\hline & $<20$ tahun & 3 & $10 \%$ \\
\hline & 20-35 Tahun & 27 & $90 \%$ \\
\hline & $>35$ tahun & 0 & 0 \\
\hline & Total & 30 & $100 \%$ \\
\hline \multirow[t]{6}{*}{2} & Pendidikan & & \\
\hline & $\overline{S D}$ & 14 & $46.7 \%$ \\
\hline & SLTP & 6 & 20,0 \\
\hline & SLTA & 6 & 20,0 \\
\hline & PT & 4 & 13,3 \\
\hline & Total & 30 & $100 \%$ \\
\hline \multirow[t]{7}{*}{3} & Pekerjaan & & \\
\hline & PNS & 2 & 6,7 \\
\hline & Wiraswasta & 5 & 16,7 \\
\hline & Karyawan & 3 & 10,0 \\
\hline & IRT & 18 & 60,0 \\
\hline & Buruh & 2 & 6,7 \\
\hline & Total & 30 & $100 \%$ \\
\hline
\end{tabular}

Berdasarkan hasil penelitian menunjukkan bahwa berdasrakan Umur bahwa mayoritas berumur 20-35 tahun sebanyak 27 (90\%) responden dan minoritas berumur $<20$ tahun sebanyak $3(10 \%)$ responden.

Berdasarkan Pendidikan bahwa mayoritas responden berpendidikan SD sebanyak 14 $(46,7 \%)$ responden, SLTP dan SLTA masing-masing $6(20 \%)$ responden, sedangkan minoritas responden dengan pendidikan terakhir perguruan tinggi hanya 4 orang $(13,3 \%)$ responden.

Menurut Pekerjaan diperoleh nahwa mayoritas respondenten bekerja sebagai IRT 18 $(60 \%)$ responden, wiraswasta $5(16,7 \%)$ responden, karyawan $3(10 \%)$ responden, sedangkan minoritas responden bekerja sebagai PNS dan buruh masing-masing hanya berjumlah $2(6,7 \%)$ responden

Analisis bivariat yang digunakan pada penelitian ini, yaitu analisis hasil uji statistic analisis Chi-square untuk melihat Pengetahuan Dan Sikap Ibu Dengan Status Gizi Selama Kehamilan Trimester Pertama

Tabel 2. Hubungan Pengetahuan dengan Status Gizi Selama Kehamilan Trimester Pertama

\begin{tabular}{|c|c|c|c|c|c|}
\hline \multirow[b]{2}{*}{ Status Gizi } & \multicolumn{4}{|c|}{ Pengetahuan } & \multirow[b]{2}{*}{$\mathbf{P}$} \\
\hline & Baik & Cukup & Kurang & Total & \\
\hline Baik & 2 & 0 & 0 & $2(6,6 \%)$ & \\
\hline Cukup & 1 & 4 & 1 & $6(20 \%)$ & 0,002 \\
\hline Kurang & 1 & 9 & 12 & $22(73,3 \%)$ & \\
\hline Total & 3 (14\%) & $13(43 \%)$ & $13(43 \%)$ & $30(100 \%)$ & \\
\hline
\end{tabular}


Tabel 3 Hubungan Sikap Ibu Hamil dengan Status Gizi Selama Kehamilan Trimester Pertama

\begin{tabular}{|c|c|c|c|c|c|c|}
\hline \multirow{2}{*}{ Status Gizi } & \multicolumn{4}{|c|}{ Sikap } & \multirow[t]{2}{*}{ Total } & \multirow[t]{2}{*}{$\mathbf{P}$} \\
\hline & Sanqat baik & Baik & Kurang baik & Tidak baik & & \\
\hline Baik & 2 & 5 & 0 & 0 & $7(23,3 \%)$ & \\
\hline Cukup & 1 & 0 & 0 & 0 & $1(3,3 \%)$ & 0,000 \\
\hline Kurang & 0 & 21 & 1 & 0 & $22(73,3)$ & \\
\hline Total & $3(10 \%)$ & $26(87 \%)$ & $1(3 \%)$ & 0 & $30(100 \%)$ & \\
\hline
\end{tabular}

Berdasarkan hasil penelitian seperti yang terlihat pada kedua tabel diatas menunjukkan bahwa nilai $p$ untuk pengetahuan dengan status gizi adalah 0,002 dan sikap dengan status gizi nilai $p=0,000$. Dikarenakan nilai $p<0,05$ berarti terdapat hubungan antara pengetahuan dan sikap dengan status gizi. Dari hasil uji ini dapat disimpulkan bahwa hipotesis penelitian ini diterima yaitu ada hubungan pengetahuan dan sikap ibu hamil dengan status gizi selama kehamilan trimester pertama.

\section{PEMBAHASAN}

Sikap adalah cara seseorang melihat sesuatu secara mental dari dalam diri dan mengarah pada perilaku yang ditunjukkan pada orang lain, ide, objek, maupun kelompok tertentu. Berdasarkan hasil penelitian dapat dilihat bahwa sikap ibu hamil dalam pemenuhan status gizi mayoritas kurang padahal pengetahuan mereka banyak yang cukup, bahkan pengetahuan baik. [Ridwan,2019]

Berdasarkan hasil penelitian yang didapatkan mayoritas sikap responden tentang gizi selama kehamilan trimester pertama di Klinik Pratama Kita Br Sembiring Namu Ukur Kec Sei Bingai Langkat Tahun 2020 bahwa mayoritas sikap responden cukup baik sebanyak 26 $(86,6 \%)$ responden, sangat baik sebanyak $3(10 \%)$ responden sedangkan minoritas responden dengan sikap kurang baik hanya $1(3,3 \%)$ responden.

Hasil ini sejalan dengan penelitian di Puskesmas Bahu Kota Manado menyatakan bahwa sebagian besar sikap ibu hamil dengan status gizi dalam kategori kurang.[Anis,2020]

Status gizi adalah ukuran keberhasilan dalam pemenuhan nutrisi bagi ibu hamil. Gizi ibu hamil merupakan nutrisi yang diperlukan dalam jumlah yang banyak untuk pemenuhan gizi ibu hamil sendiri dan juga perkembangan janin yang dikandungannya (Bobak,dkk,2005). Pertumbuhan dan perkembangan janin berasal dari ibu.[Subriah,2020]

Berdasarkan hasil penelitian didapatkan status gizi responden trimester pertama di Klinik Pratama Kita Br Sembiring Namu Ukur Kec Sei Bingai Kab Langkat Tahun 2020 bahwa mayoritas status gizi responden kurang sebanyak 22 (73,3\%) responden, cukup sebanyak 6 $(20 \%)$ responden sedangkan minoritas responden dengan baik hanya $2(36,7 \%)$ responden.

Sejalan dengan penelitian Yulianti dkk (2010) yang dilakukan di RS Panti Wilasa Citarum Semarang diperoleh sebanyak 6 orang $(15 \%)$ ibu hamil berstatus gizi buruk dengan pengukuran LILA sehingga masih didapatkan ibu hamil dengan kurang energi kronik. Namun, hasil ini tidak sejalan dengan penelitian Goni dkk (2013) bahwa prevalensi ibu hamil tentang status gizi di Puskesmas Bahu Kota Manado didapatkan mayoritas gizi ibu hamil adalah baik (62,5\%). Demikian pula dengan penelitian yang hasilnya tidak sama dengan penelitian ini bahwa sebagian besar responden mempunyai status gizi dalam kelompok tidak KEK dengan ukuran lila lebih $23,5 \mathrm{~cm}$ sebanyak 29 orang $(52,7 \%)$.

\section{Hubungan Pengetahuan dan Sikap Ibu Hamil dengan Status Gizi Selama Kehamilan Trimester I}

Berdasarkan hasil penelitian yang didapatkan ada hubungan pengetahuan ibu hamil dengan status gizi selama kehamilan trimester I $(p=0,002)$. Sehingga dapat diartikan bahwa jika pengetahuan tentang gizi baik maka status gizi ibu hamil baik pula.

Hasil uji ini sejalan dengan penelitian Goni dkk menyatakan bahwa ada hubungan pengetahuan ibu hamil dengan status gizi selama kehamilan di Puskesmas Bahu Kota 
Manado. Penelitian diperoleh hasil yang sama dengan penelitian ini bahwa hubungan yang signifikan antara pengetahuan ibu dengan status gizi ibu hamil di Puskesmas Colomadu II Karanganyar yang menyatakan hasil bahwa ada hubungan antara ibu hamil tentang status gizi dengan status gizi ibu hamil tentang gizi dengan satus gizi ibu hamil trimester III adalah signifikan (bermakna) dengan hasil koefisien kontingensi 0,415 dan $p=0.003(p, 0,050)$.

Pengetahuan yang baik pada gizi seseorang membuat orang tersebut akan semakin memperhitungkan jumlah dan jenis makanan yang dipilihnya untuk dikonsumsi. Ibu hamil yang memiliki pengetahuan gizi kurang akan berperilaku memilih makanan yang menarik panca indra dan tidak melakukan pilihan berdasarkan nilai gizi makanan tersebut. Sebaliknya mereka yang memiliki pengetahuan lebih banyak menggunakan rasional dan pengetahaun tentang nilai gizi makanan tersebut. Hal ini sejalan dengan penelitian yang dilakukan oleh Kandapati dan dari 100 sampel ibu hamil menunjukkan bahwa pengetahuan dan pola makan mempengaruhi status gizi ibu hamil.

\section{SIMPULAN}

\section{SIMPULAN DAN SARAN}

Ada hubungan pengetahuan $(p=0,002)$ dan sikap $(p=0,000)$ ibu hamil dengan status gizi selama kehamilan trimester I di Klinik Pratama Kita Br Sembiring Namu Ukur Kec. Sei Bingai Kab. Langkat Tahun 2021

\section{SARAN}

Disarankan kepada ibu hamil agar dapat meningkatkan kesadaran untuk memeriksakan serta mengontrol kehamilan kepada petugas kesehatan sehingga kemungkinan resiko kekurangan gizi selama kehamilan dapat diketahui dengan segera.

\section{DAFTAR PUSTAKA}

A. R. Metasari and K. Kasmiati, "PENGETAHUAN DAN STATUS EKONOMI BERHUBUNGAN TERHADAP STATUS GIZI IBU HAMIL DI PUSKESMAS WATAMPONE," J. JKFT, 2020, doi: 10.31000/jkft.v5i2.3916.

Masturah, "Faktor-Faktor yang Mempengaruhi Status Gizi Ibu Hamil pada Masa Kehamilan yang Berkunjung ke Puskesmas Meutulang Kecamatan Panton Reu Kabupaten Aceh Barat [skripsi]," Kesehat. Masy. Univ. Teuku Umar, 2013.

L. Sari, R. Widiasih, and $H$. Hendrawati, "GAMBARAN STATUS GIZI IBU HAMIL PRIMIGRAVIDA DAN MULTIGRAVIDA DI WILAYAH KERJA PUSKESMAS KARANG MULYA KABUPATEN GARUT," J. Keperawatan Komprehensif (Comprehensive Nurs. Journal), 2020, doi: 10.33755/jkk.v6i2.173.

P. Fransiska, "Hubungan Antara Pengetahuan dan Status Gizi Ibu Hamil dengan Kejadian Pre Eklamsia pada Ibu Hamil," Citra Delima J. IIm. STIKES Citra Delima Bangka Belitung, 2020, doi: 10.33862/citradelima.v4i1.100.

Anis Ervina and D. Juliana, "Hubungan Status Gizi Ibu Hamil Dengan Kejadian Anemia Pada Ibu Hamil," J. Obs. Sci., 2017.

SDKI, "Survei Demografi dan Kesehatan 2017," Ris. Kesehat. Dasar 2018, 2017.

I. N. Ibnu, "Hubungan Sosial Demografi, Keanekaragaman Pangan dengan Status Gizi Ibu Hamil di Sulawesi Selatan," Ghidza J. Gizi dan Kesehat., 2020, doi: 10.22487/ghidza.v4i1.45.

E. M. Puspitaningrum, "HUBUNGAN PENGETAHUAN DENGAN STATUS GIZI IBU HAMIL DI PUSKESMAS TANJUNG PINANG KOTA JAMBI," JI-KES (Jurnal IImu Kesehatan), 2017, doi: 10.33006/ji-kes.v1i1.53.

E. M. Pusitaningrum, "Hubungan status gizi ibu hamil dengan kejadian Berat Badan Lahir Rendah (BBLR )di RSIA ANNISA kota Jambi tahun 2018," secientia, 2018.

A. Aguscik and R. Ridwan, "PENGARUH STATUS GIZI TERHADAP KEJADIAN ANEMIA PADA IBU HAMIL DI DAERAH ENDEMIK MALARIA KOTA BENGKULU," JPP (Jurnal Kesehat. Poltekkes Palembang), 2019, doi: 10.36086/jpp.v14i2.417.

Anis Ervina and D. Juliana, "HUBUNGAN STATUS GIZI IBU HAMIL DENGAN KEJADIAN HIPERTENSI DI PUSKESMAS SULILI,” J. Kesehat. Luwu Raya, 2020.

S. Subriah, H. Hidayati, and Z. A. Amdadi, "STATUS GIZI IBU HAMIL TRIMESTER III DI 
PUSKESMAS MANGASA KOTA MAKASSAR," Media Kesehat. Politek. Kesehat. Makassar, 2020, doi: 10.32382/medkes.v15i1.697. 